\title{
Spontaneous External Digestive Fistula of Tuberculosis Origin, Medical Treatment: About a Case at the Timbuktu Hospital
}

\author{
Oumar Ongoïba1, Idrissa Tounkara ${ }^{2 *}$, Thiam Souleymane ${ }^{3}$, Charles Dara1, Jacques Saye4, \\ Karim Dao', Djibril Kassogué ${ }^{1}$
}

${ }^{1}$ Timbuktu Mali Regional Hospital Mali, Timbuktu, Mali

${ }^{2}$ Reference Health Center of Commune II, Bamako, Mali

${ }^{3}$ Gao Regional Hospital, Gao, Mali

${ }^{4}$ Point G University Hospital Center, Bamako, Mali

Email: ^idrisstounk@yahoo.fr

How to cite this paper: Ongoiba, O., Tounkara, I., Souleymane, T., Dara, C., Saye, J., Dao, K. and Kassogué, D. (2021) Spontaneous External Digestive Fistula of Tuberculosis Origin, Medical Treatment: About a Case at the Timbuktu Hospital. Surgical Science, 12, 17-22.

https://doi.org/10.4236/ss.2021.121003

Received: December 2, 2019

Accepted: January 26, 2021

Published: January 29, 2021

Copyright $\odot 2021$ by author(s) and Scientific Research Publishing Inc. This work is licensed under the Creative Commons Attribution International License (CC BY 4.0).

http://creativecommons.org/licenses/by/4.0/

\begin{abstract}
In the literature, the management of enterocutaneous fistula of tuberculosis origin is rare. The aim of this work was to report a case of external digestive fistula of tuberculosis origin in a 10-year-old girl in northern Mali in a situation of armed conflict. She was a 10 -year-old patient who was admitted to our general surgery ward for external digestive fistula evolving for more than (4) four years, at admission the general. The karnofsky index was at $40 \%$, she could not sit or hold a cup to drink water. A $3 \mathrm{~cm}$ enterocutaneous fistula deafened foul-smelling liquid stools, on clinical examination, the conjunctivas were pale, the lips were dry, the eyes were sunk in the eye sockets, the ribs visible from a distance. The paraclinical aspects (Itra-Dermo-Reaction (IDR) to tubercria, anatomopathology) were positive, specifying the place of medical treatment and evolution under medical treatment. Digestive fistula of tuberculosis origin is a rare condition in surgical settings.
\end{abstract}

\section{Keywords}

Spontaneous External Digestive Fistula, Non-Surgical Treatment, Timbuktu

\section{Introduction}

Tuberculosis remains a major cause of morbi-mortality worldwide, with large disparities between regions and populations according to the World Health Organization (WHO), the second leading cause of infectious mortality in the world, after human immunodeficiency virus (HIV) infection, causing 1.3 million 
deaths in 2010 [1]. They are caused by microorganisms that are at least resistant to isoniazide and rifampicin [2] [3]. More than $60 \%$ of these patients lived in the People's Republic of China, Republic of India, Russian Federation, Islamic Republic of Pakistan and Republic of South Africa [4]. In total, 84 countries have reported cases of extensively drug-resistant tuberculosis [5]. The exclusively extra-respiratory forms involved $12 \%$ of cases [1]. The main factors for amplification of the epidemic are rural exodus, malnutrition and unsanitary conditions [6]. The effectiveness of antibiotic treatment is excellent [7]. For digestive tuberculosis, contamination of the digestive tract is done by swallowing contaminated secretions. The entire digestive tract can be affected, from the mouth to the anus, with lesions ranging from ulceration to pseudo-tumor mass. The disease can progress to hemorrhage, obstruction, fistulization, perforation and cause severe malabsorption disorders. Adequate time for action should be given to TB controls before considering surgery [7]. The natural reaction against $M$. Tuberculosiscomplex mainly requires a cellular-mediated immune response. Any immunodepression (aging, stress, severe malnutrition, chemotherapy and other immunosuppressive treatments, prolonged corticosteroid therapy, organ transplants, chronic kidney failure, malignant hemopathies, HIV infection) promotes the development of tuberculosis [8]. Digestive impairment may be primitive by direct ingestion of mycobacterium or secondary to very bacillous lung lesions by hematogen or lymphatic [9]. Female predominance is found in intestinal locations [10]. Extra-pulmonary TB accounts for nearly $1 / 3$ of reported TB cases [11]. It sits in order of decreasing frequency, at the lymph node, genitourinary, osteo-articular and digestive level [12].

\section{Observation}

This was a 10-year-old patient who was admitted to our general surgery department for external digestive fistula evolving for more than four (4) years, at admission a general cachectic condition, a karnofsky index of $40 \%$, she could not sit or hold a cup to drink water. A $3 \mathrm{~cm}$ enterocutaneous fistula made of foul-smelling liquid stool, on clinical examination that we have appeared (Figure 1). The conjunctivas were pale, lips dry, eyes sunk, 100\% oxygen saturation, heart rate of 136 beats per minute, respiratory rate which was 26 cycles per minute, temperature of $36.5^{\circ} \mathrm{C}$, Glasgow $15 / 15$, weight of $11 \mathrm{~kg} 900$ and target weight to reach was $15,800 \mathrm{~kg}$, size $108.5 \mathrm{~cm}, \mathrm{P} / \mathrm{T}(\mathrm{Z} / \%)<-3$, P.B $95 \mathrm{~mm}$.

The sounds of the heart were audible, regular, at the pulmonary level, the vesicular murmurs were well perceived without crackling rails. The abdomen was distended with collateral venous circulations, a tusure of both flanks and epigastre, a redness all to the turns of the fistula hole with significant ulcerations, a multiple abdominal mass of firm consistency more accentuated in both flanks and epigastric region without organomegaly (Hepato-splenomegaly), multiple bilateral axillary curd-like and non-fistula bilateral adenopathic macro-adenopathy fistulized of both armpits, hard, painful little mobile about $5 \mathrm{~cm}$ 


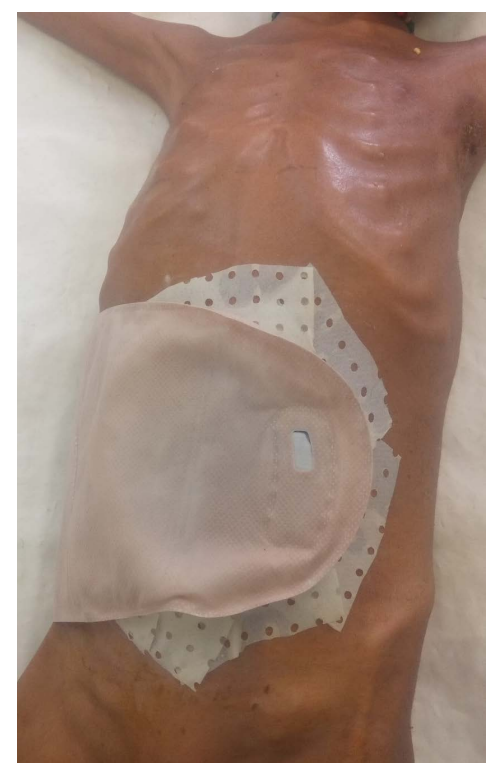

Figure 1. Appeared digestive fistula.

or more.

We accepted the diagnostic hypothesis of an external digestive fistula of typhic origin associated with severe acute malnutrition. Additional examinations. For undernutrition we asked the opinion of a nutritionist who had requested an appetite test with plumpinut for the management of severe acute malnutrition, after $48 \mathrm{H}$, the appetite test to fail, a lymph node biopsy to raise an adeheritis caseo-follicular tb. Absence of histological signs of malignancy at the edge of the fragments examined, a tuberculin-positive IDR-10 $\mathrm{cm}$, retroviral serology is negative, white blood cell count $12.00 \mathrm{M} / \mathrm{mm}^{3}$ [3.5 - 10.0], Polynuclear neutrophile at 77\% [60 - 75], Globule red at 2.45M [3.8 - 5.8], hemoglobin levels at 6.9 g/dL [11 - 16.5]. A normocytic normochrome anemia associated with nutrophile polynuclear hyperleucocytosis. After confirming the diagnosis of fistulized pseudotumor peritoneal tuberculosis, we carried out pre-therapeutic assessments of creatininemia $0.7 \mathrm{mg} / \mathrm{dl}$ [0.6 - 1.1], Transaminase GOT 34 IU/L [45 IU/L] GPT 23 IU/L [40 UI/L], Bilirubin total $0.11 \mathrm{mg} / 1$ [0.11 mg/l, Bilirubin direct conjugate $0.24 \mathrm{mg} / \mathrm{L}[0.25 \mathrm{mg} / \mathrm{L}]$.

The therapeutic protocol in the attack phase was RHZE for a period of 2 months and then HR for a period of 4 months of treatment. During the evolution, a decrease in weight up to $9 \mathrm{~kg}$, then a gradual increase to $18 \mathrm{~kg}$ that day, a change in the temperature in saw tooth then stabilization and normalization of the temperature and a gradual decrease in the flow of fistula by $1 \mathrm{~L}$ per day until the fistula closes this day after 3 months of treatment (Figure 2).

\section{Discussion}

The abdominal location is relatively frequent and represents $5 \%$ to $10 \%$ of all locations [6]. The symptomatology is no specific and the palpation of an abdominal mass can guide everything towards a malignant tumor pathology, especially 


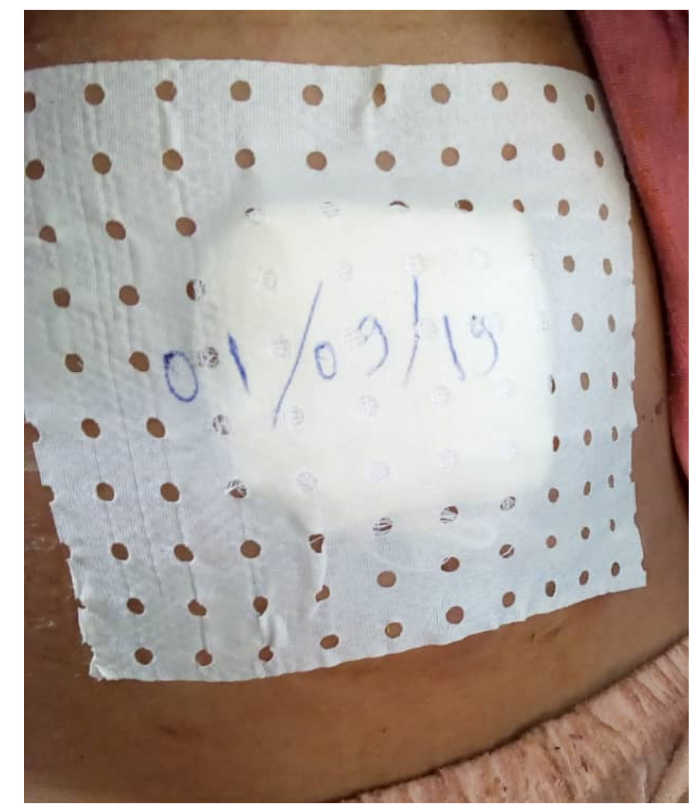

Figure 2. Closed digestive fistula.

as the symptomatology evolves in a context of deterioration of the general state. This difficult and frequently unknown diagnosis must be mentioned especially in the epidemiological context lends itself to it [7], in the presence of concomitant pulmonary involvement, or in the presence of a history of tuberculosis. The pseudo-tumoral forms of abdominal tuberculosis are rarely reported in the literature causing a diagnostic delay and consequently the persistence of the evolution of this normally curable disease.

The authors therefore considered it useful to report five cases of pseudo-tumoral abdominal tuberculosis and to highlight the diagnostic and therapeutic aspects. In the course of abdominal tuberculosis all organs can be reached and the most usual localizations of digestive tuberculosis are the small intestine (44\%), it was the same in our study; the coecum (35\%) and the ileocoecum (16\%) [8].

Isolated involvement of the colon is rare, it is estimated between $2 \%-9 \%$ and dominated by the involvement of the right colon [9]. Digestive involvement can be primitive by direct ingestion of mycobacterium or secondary to highly bacilliferous pulmonary lesions by hematogenous or lymphatic route [10]. The bacterial agent is most often the bovine or human koch bacillus, exceptionally atypical mycobacteria in immunocompromised individuals [3]. Female predominance is found in intestinal localizations [7]. Tuberculosis, despite its prevention, remains a widespread affection, especially in certain regions: Africa, Asia, India [2]. The digestive tract is the 3rd extra-pulmonary localization of tuberculosis after the pleural and ganglionic localization. Its frequency remains high in developing countries and has increased in industrialized countries [WHO Global Tuberculosis Report 2016. The digestive tract is the 3rd extra-pulmonary localization of tuberculosis after the pleural and ganglionic localization. Its frequency 
remains high in developing countries and has increased in industrialized countries [WHO Global Tuberculosis Report 2016. Despite its rarity, intestinal tuberculosis is still relevant. This localization poses diagnostic problems because of its rarity but also because of the difficulties of isolation of the germ [8]. Diagnosis of intestinal tuberculosis is important to establish because medical treatment is very effective [10]. The diagnosis of pseudo-tumoral abdominal tuberculosis should be mentioned especially in an endemic country such as ours and the use of laparotomy is justified whenever a diagnostic doubt persists or in case of complication [5].

\section{Conclusion}

Digestive fistula of tuberculosis origin is a rare condition in surgical settings. Medical management combined with good enteral nutrition of confirmed cases yields very good results.

\section{Conflicts of Interest}

The authors declare no conflicts of interest regarding the publication of this paper.

\section{References}

[1] Antoine, D. and Che, D. (2012) Les cas de tuberculose déclarés en France en 2010. Bulletin Epidemiologique Hebdomadaire, 24-25, 285-287.

[2] Zumla, A., Raviglione, M., Hafner, R., et al. (2013) Tuberculosis. The New England Journal of Medicine, 368, 745-755. https://doi.org/10.1056/NEJMra1200894

[3] World Health Organization (2012) Global Tuberculosis Report 2012. World Health Organization, Geneva.

[4] Zignol, M., van Gemert, W., Falzond, D., et al. (2012) Surveillance of Anti-Tuberculosis Drug Resistance in the World: An Updated Analysis, 2007-2010. Bull World Heath Organ, 90, 111-119D. https://doi.org/10.2471/BLT.11.092585

[5] World Health Organization Commnicable DISEASES CLUSTER, STOP TB DEPT (2011) TOWARDS Universal Access to Diagnosis and Treatment of Multidrug-Resistant and Extensively Drug-Resistant Tuberculosis by 2015 WHO Progress Repport 2011. World Health Organization, Geneva.

[6] World Health Organization (2012) Global Tuberculosis Control 2011. World Health Organization, Geneva.

[7] Dye, C., Scheele, S., Dolin, P., et al. (1999) Consensus Statement. Global Burden of Tuberculosis: Estimated Incidence, Prevalence, and Mortality by Country. JAMA, 282, 677-686. https://doi.org/10.1001/jama.282.7.677

[8] Brudney, K. and Dobkin, J. (1991) Resurgent Tuberculosis in New York City. Human Immunodeficiency Virus, Homelessnes, and the Decline of Tuberculosis Control Programs. American Review Respiratory Disease, 282, 677-686.

[9] Mc Nerney, R., Maeurer, Abubakar, I., et al. (2012) Tuberculosis Diagnostics and Biomarkers: Needs Challenges, Recent Advances, and Opportunities. The Journal of Infectious Diseases, 205, S147-S158. https://doi.org/10.1093/infdis/jir860

[10] Billy, C. and Perronne, C. (2004) Aspects cliniques et thérapeutiques de la tuberculose chez l'enfant et l'adulte. EMC-Maladies Infectieuses, 1, 81-98. 
https://doi.org/10.1016/j.emcmi.2004.01.002

[11] Billy, C. and Perronne, C. (2002) Treatment of Tuberculosis Infection. Ann Med Interne (Paris), 153, 119-127.

[12] Working Group of the Higher Council of Public Hygiene in France (2004) Treatment of Tuberculosis-Disease. Medicine and Infectious Diseases, 34, 375-381. 